$\left[\begin{array}{l}\text { Jpn. J. Hosp. Pharm. } \\ \overline{19} \text { (4) } 303-309 \text { 論 } \\ \text { (1993) }\end{array}\right]$

塩酸モルヒネ末または水溶液充垻中空坐剂の調製と評価 $\dagger^{1,2}$

\author{
松本宜明 $* \uparrow^{3}$, 渡辺善照 $\dagger^{3}$, 山本郁生 $\dagger^{3}$, 谷田部聡子 $\uparrow^{3}$, 石井恭子 $\dagger^{3}$,

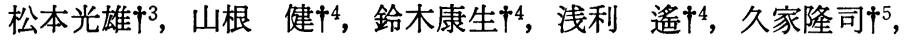

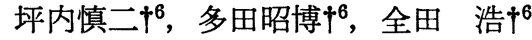 \\ 昭和薬科大学薬剤学 $\dagger^{3}$ \\ 東邦大学医学部附属大橋病院第二麻酔科学 $\dagger^{4}$, 同薬剤部 ${ }^{5}$ \\ 信州大学医学部附属病院薬剤部 ${ }^{+6}$
}

\title{
Preparation and Evaluation of Hollow-type Suppositories \\ Containing Morphine Hydrochloride Powder or Solution $\dagger^{1,2}$
}

\author{
Yoshiaki MATSUMOTO ${ }^{*} \dagger^{3}$, Yoshiteru WATANABE $\dagger^{3}$, IKUO Yamamoto ${ }^{3}$, \\ SATOKO YATABE $\dagger^{3}$, KYOKO Ishi $\dagger^{3}$, Mitsuo MATSUMOTO ${ }^{3}$,

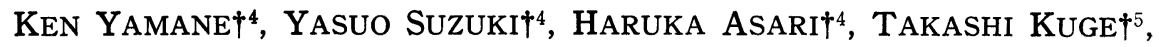 \\ SHINJI TSUBOUCHI ${ }^{6}$, AKIHIRO TADA ${ }^{6}$, HIROSHI ZENDA ${ }^{6}$ \\ Department of Pharmaceutics, Showa College of Pharmaceutical Sciences $\dagger^{3}$ \\ Second Department of Anesthesiology, Toho University, School of Medicine $\dagger^{4}$ \\ Department of Pharmacy, Toho University Ohashi Hospital $\dagger^{5}$ \\ Department of Pharmacy, Shinshu University Hospital $\dagger^{6}$
}

(Received March 1, 1993)

The bioavailability of morphine following rectal administration of a hollow-type suppository containing morphine hydrochloride $(10 \mathrm{mg})$ in different-added forms was evaluated in patients under general anesthesia during operation. The hollow-type suppositories were prepared using Witepsol $\mathrm{H}-15$, a suppository containing $1 \%$ morphine solution (morphine solution, $10 \mathrm{mg} / \mathrm{ml}$ ) or $10 \%$ morphine powder diluted with lactose (morphine powder, $100 \mathrm{mg}$ ) in its cavity. The plasma concentration of morphine and its metabolite, morphine-3-glucuronide (M-3-G), were determined.

The mean $\mathrm{C}_{\max }$ and $\mathrm{AUC}$ of morphine following rectal administration of the hollow-type suppository containing morphine solution were higher than those obtained from the suppository containing morphine powder, whereas the mean $\mathrm{C}_{\max }$ and $\mathrm{AUC}$ of $\mathrm{M}-3-\mathrm{G}$ were lower than those following administration of the suppository containing morphine powder. The mean AUC ratio of M-3-G to morphine following administration of the morphine-powder containing suppository was three times larger than that of the suppository containing morphine solution. The hollowtype suppository containing morphine solution or powder could thus be useful for the pain control of patients with cancer.

These findings suggest that the hollow-type suppository containing morphine powder or solution, which could be adjusted to specific individual dosages, constitutes a useful clinical application for the cancer patient from the viewpoint of enhancing the quality of life.

Keywords-rectal morphine absorption; morphine-3-glucuronide; first-pass elimination hollow-type suppository; surgical operation 


\section{緒言}

近年, 癌疼痛, 術後疼痛, 慢性疼痛などの疼痛 管理に损いて，簡便な坐剂による治療が注目さ れ，治療手段2,3) として多く用いられている。1992 年塩酸モルヒネ坐剂(4) が市販され，多くの施設で 使用されている．著者らは，中空坐剤を用いた塩 酸モルヒネ坐剂を今まで多く院内製剤5)として使 用している。一方, 塩酸モルヒネの中空坐剤中空 部への充填方法は施設により異なり，塩酸モルヒ ネ水溶液5) または塩酸モルヒネー乳糖10倍散で調 製6)を行っている．本研究では周術期における塩 酸モルヒネ水溶液または塩酸モルヒネー乳糖10倍 散充媜坐剂投与後のモルヒネおよびその代謝物 morphine-3-glucuronide (M-3-G) の体内動態 を調べ比較した。さらに水溶液充填坐剤の症例に ついて検討を行った。

\section{実 験 の 部}

\section{1. 試料}

塩酸モルヒネ末または注射液は武田薬品工業, 乳糖は吉田製薬から購入した，坐剤基剤（Witepsol H-15 (H-15)) はミツバ貿易から供与され たものを用いた，M-3-G は九州大学から，塩酸 ナロルフィンは大日本製薬から譲渡されたものを 用いた。 その他の試薬は市販特級試薬を用いた。

\section{2. 坐剤の調製}

紡錘型 $\left(2.1 \mathrm{~g}\right.$ ，中空部容積 $\left.0.5 \mathrm{~cm}^{3}\right)$ または砲 弾型 $\left(2.1 \mathrm{~g}\right.$, 中空部容積 $\left.1 \mathrm{~cm}^{3}\right)$ の中空坐剤は, 中空部形成用アダプターを装着した金属製坐剂成 形器を使用して先の報告7) に準じて調製した。塩 酸モルヒネ水溶液を用いる場合は 1 回の投与量を

$\dagger^{1}$ 本報を「中空坐剤の製剂学的評価（第17報)」12 する.

$\dagger^{2}$ 本研究の一部は第 2 回日本病院薬学会年会 (東京, 1992年 7 月）で発表.

$\dagger^{3}$ 東京都町田市東玉川学園3-3165; 3-3165, Higashitamagawagakuen, Machida, Tokyo, 194 Japan

$\dagger^{4,5}$ 東京都目黒区大橋2-17-6; 2-17-6, Ohashi, Meguro-ku,Tokyo, 153 Japan

† 6 長野県松本市旭3-1-1; 3-1-1, Asahi, Matsumoto, Nagano, 390 Japan
蒸留水に溶解したものまたは注射液 $(10 \mathrm{mg} / \mathrm{ml})$ を用い，中空部容積 0.5 または $1 \mathrm{~cm}^{3}$ の坐剤に充 媜した．塩酸モルヒネをあらかじめ乳糖で10倍散 に予製した粉末を紡錘型中空坐剂に充媜（塩酸モ ルヒネ - 乳糖10倍散充填）した。

\section{3. 周術期患者}

東邦大学医学部附属大橋病院において婦人科ま たは整形外科手術が施行された ASA 分類 I また はII で貧血を認めない患者 8 例を Table 1 に示 す．術中採血は先の報告8) と同様に行った．すな わち全身麻酔は笑気-酸素-エンフルレン (GOĒ), イソフルェン (GOI) またはセボフルェン (GOS) で行い，患者には麻酔補助の目的で坐剤の投与拉 よび術中採血を行うことを口頭で説明し承諾を 得た. 全身麻酔導入直後, 坐剂 1 個を示指一遠位一 関節まで挿入し経時的に採血を行った。

\section{4. 入院患者}

信州大学医学部附属病院に入院していた患者 4 名を Table 2 に示す.

\section{5. 血采中モルヒネ灌度測定}

血漿中からの塩酸モルヒネおよび M-3-G の測 定方法は, Svensson の報告9) に準じた。すなわ ち, SEP-PAKtC18 (Waters Chromatography Div. Millipore)を用い,メタノール，試料 血漿 $0.5 \mathrm{ml}$ を加兄，内部標準物質に塩酸ナロル フィン $(2.5 \mu \mathrm{g} / 50 \mu \mathrm{l})$ を添加し，蒸留水および 5 \%アセトンで処理した. $70 \%$ メノールで溶出し た液を窒素ガス気流下 $60^{\circ} \mathrm{C}$ で蒸発乾固後, 移動

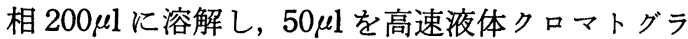
フ (HPLC) に注入し測定した.

\section{HPLC 測定条件}

移動相 は $10 \mathrm{mM}\left[\mathrm{NaH}_{2} \mathrm{PO}_{4}(\mathrm{pH} 2.1)+1 \mathrm{mM}\right.$ $\mathrm{SDS}$ ] : $\mathrm{CH}_{3} \mathrm{CN}(3: 1)$ を用い，カラムは TSK gel ODS-120T $(150 \times 4.6 \mathrm{~mm}$ i.d., 東ソー) 用い, カラム温度 $40^{\circ} \mathrm{C}$ で $\mathrm{HPLC}$ 用送液ユニット （LC-6A，島津製作所）により流速 $1 \mathrm{ml} / \mathrm{min}$ と 乙, 電気化学検出器 $(E C D,+0.8 \mathrm{~V}$, 島津製作 所) および紫外分光光度検出器 (SPD, $210 \mathrm{~nm}$, 島 津製作所）を用いて測定した。モルヒネの測定限 界は, $1 \mathrm{ng} / \mathrm{ml}, \mathrm{M}-3-\mathrm{G} は, 30 \mathrm{ng} / \mathrm{ml}$ であった。 データ処理装置（クロマトパック C-R4A，島津 
Table 1. Patient Characteristics

\begin{tabular}{ccclll}
\hline \hline Case No. & Age & Sex & $\begin{array}{l}\text { Body Weight } \\
(\mathrm{kg})\end{array}$ & Oparation & $\begin{array}{l}\text { General } \\
\text { Anesthesia }\end{array}$ \\
\hline 1 & 59 & $\mathrm{M}$ & 61 & Total gastrectomy & GOS \\
2 & 66 & $\mathrm{~F}$ & 64 & Cholecystectomy & GOE \\
3 & 40 & $\mathrm{~F}$ & 44 & Hysterectomy & GOI \\
4 & 38 & $\mathrm{~F}$ & 53 & Hysterectomy & GOS \\
5 & 49 & $\mathrm{~F}$ & 60 & Mastectomy & GOI \\
6 & 51 & $\mathrm{~F}$ & 45 & Tympanoplasty & GOS \\
7 & 43 & $\mathrm{~F}$ & 50 & Mastectomy & GOS \\
8 & 68 & $\mathrm{~F}$ & 40 & Hysterectomy & GOI \\
\hline
\end{tabular}

Table 2. Patient Characteristics and Plasma Concentrations after Morphine Administration

\begin{tabular}{|c|c|c|c|c|c|c|c|c|c|}
\hline Case & Age & Sex & $\begin{array}{l}\text { Body } \\
\text { Weigh } \\
\text { (kg) }\end{array}$ & Diagnosis & Administration $^{\text {a) }}$ & $\begin{array}{l}\text { One Dose } \\
(\mathrm{mg})\end{array}$ & $\begin{array}{l}\text { Daily Dose } \\
\text { (mg/day) }\end{array}$ & $\begin{array}{l}\text { Sampling } \\
\text { Time after } \\
\text { Administration }\end{array}$ & $\begin{array}{l}\text { Plasma } \\
\text { morphine } \\
\text { Concn. } \\
\text { (ng/ml) }\end{array}$ \\
\hline \multirow[t]{2}{*}{ A } & 66 & $M$ & 64 & $\begin{array}{l}\text { Prostatic } \\
\text { cancer }\end{array}$ & Suppository & 10 & 40 & 1 & 37 \\
\hline & & & & & & & & 3 & 14 \\
\hline \multirow[t]{2}{*}{ B } & 63 & $\mathrm{~F}$ & 46 & $\begin{array}{l}\text { Uterine } \\
\text { cancer }\end{array}$ & Suppository & 50 & 200 & 1 & 177 \\
\hline & & & & & & & & 3 & 169 \\
\hline \multirow[t]{2}{*}{ C } & 65 & $M$ & 50 & $\begin{array}{l}\text { Colon } \\
\text { cancer }\end{array}$ & Oral & 50 & 100 & 1 & 23 \\
\hline & & & & & Suppository & 20 & 80 & 3 & 24 \\
\hline \multirow[t]{2}{*}{ D } & 58 & $\mathrm{~F}$ & $35 \mathrm{E}$ & $\begin{array}{l}\text { Esophagus } \\
\text { Eancer }\end{array}$ & Oral & 180 & 360 & 3 & 19 \\
\hline & & & & & Suppository & 40 & 160 & 3 & 80 \\
\hline
\end{tabular}

a) Suppository: Hollow-type suppository containing morphine solution Oral: Sustained-release tablet

製作所）を用いピーク高さを測定し内部標準を用 いてモルヒネ濃度を算出した.

\section{7. デー夕解析}

最高血漿中濃度 $\left(\mathrm{C}_{\max }\right), \mathrm{C}_{\max }$ に到達するまで 飞要する時間 $\left(t_{\max }\right)$ は投与後の血漿中濃度-時間 曲線から求めた。モルヒネ拈よび $\mathrm{M}-3-\mathrm{G} の$ 血漿中 濃度-時間曲線下面積 (AUCmo $\mathrm{AL}_{0-2}, \mathrm{AUC} \mathrm{AG}_{0-2}$ ) はそれぞれの血漿中濃度 - 時間曲線の 0 から 2 時 間までを台形則に従い算出した。

統計学的解析は分散分析を行った後 Dunnett
法により有意差を検定した $\mathrm{p}<0.05$ の場合を有意 差ありと判定した.

\section{結果および考察}

\section{1. 塩酸モルヒネ水溶液充埧坐剤投与後の血采} 中濃度

Fig. 1 に周術期(症例 1-4) に打ける塩酸モル ヒネ $10 \mathrm{mg}$ 注射液充填坐剂投与後の血漿中濃度時間曲線を示す．これらの坐剂投与後のモルヒネ 体内動態パラメータを Table 3 に示す. 
モルヒネは投与後15分から検出され, 平均 $\mathrm{C}_{\max }$ は $39 \mathrm{ng} / \mathrm{ml}$, 平均 $\mathrm{t}_{\max }$ は $41 \mathrm{~min}$, 平均 $\mathrm{AUCmo}_{0-2}$ は $38 \mathrm{~h} ・ \mathrm{ng} / \mathrm{ml}$ を示した. 塩酸モルヒネを注射液 のまま充媜した坐剤においてモルヒネの吸収は認 められた。

信州大学医学部附属病院では塩酸モルヒネ水溶 液充填中空坐剂をこれまで多く用いている5). 信 州大学医学部付属病院に括ける末期癌患者に拈い て, 塩酸モルヒネ水溶液を充填した中空坐剂を用 いた症例拉よび血墏中モルヒネ濃度を Table 2 に示す. 症例 Aは 1 回 $10 \mathrm{mg}, 1$ 日 4 回の投与で, モルヒネの血漿中濃度は投与後 1 時間で $37 \mathrm{ng} /$ $\mathrm{ml}, 3$ 時間で $14 \mathrm{ng} / \mathrm{ml}$ を示した. 1 回の投与量 が $50 \mathrm{mg}$ の症例Bでは, 投与後 1 時間で $177 \mathrm{ng} /$ $\mathrm{ml}, 3$ 時間で $169 \mathrm{ng} / \mathrm{ml}$ を示した. 市販徐放錠 から坐剤へ变更した症例 Cおよび $\mathrm{D}$ の場合, 投与 量は減量でき, 血漿中濃度は高く認められ, 臨床 効果はほぼ同等またはそれ以上であることが明ら かとなった. Konishi ら る経口投与後と直腸投与後の血漿中モルヒネ濃度 は大きく異ならないことが報告されているが， Ellison ら ${ }^{11)}$ の報告と同様に, 本研究における直 腸投与後の血墏中モルヒネ濃度は経口投与に比べ 高いことが明らかとなった。 さらに, 経口投与か らモルヒネー乳糖10倍散を充填した中空坐剤に変 更した場合，投与量が減量できた報告 ${ }^{12)}$ と同様な 結果と考えられる. 1 回の投与量に沶いて市販坐 剤の用量 $(10,20 \mathrm{mg})$ を大きく越える高投与量が 必要な場合，中空坐剤は中空部に充媜する塩酸モ ルヒネ量を容易に増量することができる製剤とし て有用と考えられる。

\section{2. 塩酸モルヒネー乳糖10倍散充塹坐剤投与後} の血浆中濃度

周術期（症例 5-8）に拈ける塩酸モルヒネー乳糖 10倍散充媜坐剂投与後の血漿中濃度 - 時間曲線を Fig. 2 に示す. 坐剤投与後のモルヒネ体内動態 パラメータを Table 4 に示す.

周術期における塩酸モルヒネー乳糖10倍散充填 坐剤投与後は水溶液充媜と異なり, モルヒネは投 与後15分では検出されなかったが，45分以降から 検出された. しかし, 症例 7 に括いてはモルヒネ
は検出されなかった。

本研究に打ける粉末充填の平均 $\mathrm{AUCmo}_{0-2}$ は $20 \mathrm{~h} \cdot \mathrm{ng} / \mathrm{ml}$ を示し，水溶液に比べ低い值となっ たが，著者らが報告した12）ブロンプトン液（15$240 \mathrm{mg} / 100 \mathrm{ml}$ ) 投与から塩酸モルヒネー乳糖10倍 散充填中空坐剤に变更した症例に打いて, 塩酸モ ルヒネの投与量を約 $1 / 3$ に減量でき, 十分な臨床 効果が認められている. 一方, ウサギにおける坐

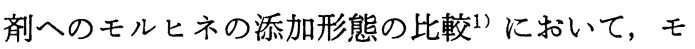
ルヒネ原末を充填した場合, 水溶液 $(10 \mathrm{mg} / 0.5$ $\mathrm{ml})$ に比べ生物学的利用能が高いことを認めてい る.このことは各坐剤より局所の粘膜表面に存在 する少量の直腸内液中に塩酸モルヒネが溶出する 場合, 原末の方が粉末量の多い10倍散よりもモル ヒネの溶出が速いためモルヒネの局所濃度が投与 初期には高くなるためと考えられる.ささらに周術 期は，筋弛緩薬の併用および体位の動きが少ない ことに留意する必要があると考えられる。

3. 塩酸モルヒネー乳糖10倍散または水溶液充 埧坐剤における M-3-G 体内動態の比較

モルヒネの主な代謝物にはグルクロン酸抱合体 の M-3-G および活性代謝物の morphine-6glucuronide $(M-6-G)^{13)}$ があるが, 本研究では 粉末充填坐剤と水溶液充媜坐剤投与後における $\mathrm{AUCmo}_{0-2}$ が異なることから血墏中にモルヒネ および M-6-G に比べ著しく多く検出される $\mathrm{M}-$ 3-G について測定した。 血墏中 $M-3-G$ 濃度-時 間曲線を Fig. 1 または 2 にそれぞれ併記した。 これらの体内動態パラメータを Table 3 をたは 4 に併記した。

坐剂投与後の $\mathrm{M}-3-\mathrm{G}$ の $\mathrm{C}_{\max }$ 㧊よび $\mathrm{AUC}$ $3 \mathrm{G}_{0-2}$ はモルヒネに比べ著しく大きく認められた ことから, 周術期に拈いてモルヒネの血墏中濃度 が低いことは，モルヒネの直腸に拈ける吸収不全 ではなく大部分のモルヒネが代謝を受けているこ とが明らかとなった. 水溶液充填の場合, 投与後 15分においてモルヒネまたは M-3-G のいずれか は認められた。水溶液充填坐剂の速い吸収は, 塩 酸プロプラノロール水溶液充填坐剤14)においても 同様に認め, 坐剤側壁の基剤の一部が融解すれ ば，中空部にある薬物の水溶液は直ちに放出され 

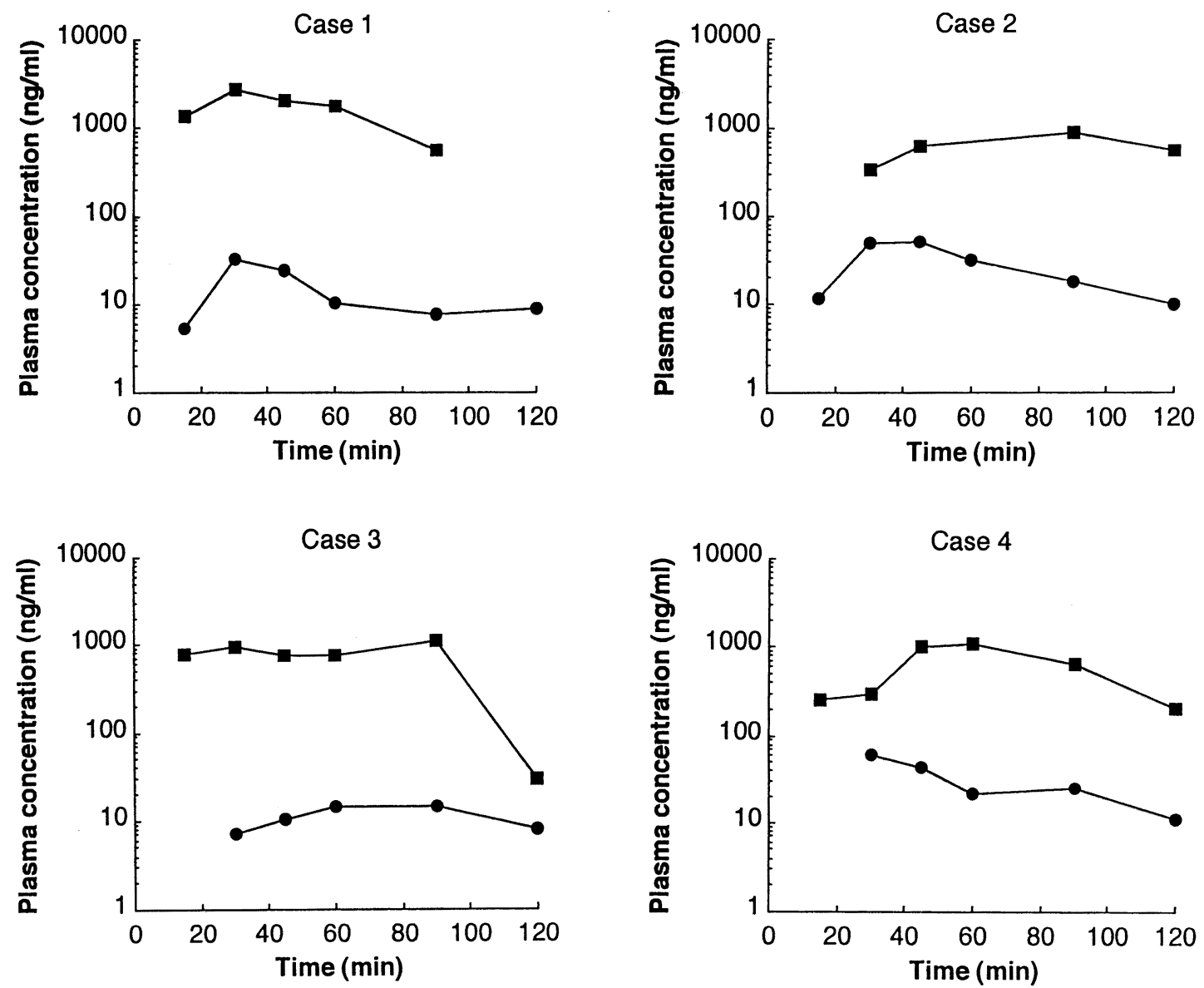

Fig. 1. Plasma Concentration-Time Curves of Morphine and M-3-G following Rectal Administration of Hollow-Type Suppository Containing Morphine Hydrochloride Solution in Patients (No. 1-4) under General Anesthesia during Surgical Operation

Key: $\bullet$, morphine; $\square, \mathrm{M}-3-\mathrm{G}$.

Table 3. Pharmacokinetic Parameters of Morphine and M-3-G following Rectal Administration of Hollow-Type Suppository Containing Morphine Solution

\begin{tabular}{|c|c|c|c|c|c|c|c|}
\hline \multirow[b]{2}{*}{$\begin{array}{l}\text { Case } \\
\text { No. }\end{array}$} & \multicolumn{3}{|c|}{ Morphine } & \multicolumn{3}{|c|}{$M-3-G$} & \multirow{2}{*}{$\begin{array}{l}\text { AUC ratio } \\
\text { M-3-G/ } \\
\text { Morphine }\end{array}$} \\
\hline & $\begin{array}{l}\text { Cmax } \\
(\mathrm{ng} / \mathrm{ml})\end{array}$ & $\begin{array}{l}t \operatorname{tmax} \\
(\min )\end{array}$ & $\begin{array}{l}\text { AUCMO0-2 } \\
(\mathrm{h} \cdot \mathrm{ng} / \mathrm{ml})\end{array}$ & $\begin{array}{l}\max \\
(\mathrm{ng} / \mathrm{ml})\end{array}$ & $\begin{array}{l}t \operatorname{tmax} \\
(\min )\end{array}$ & $\begin{array}{l}\text { AUC3G0-2 } \\
\text { (h.ng/ml) }\end{array}$ & \\
\hline 1 & 32 & 30 & 25 & 2740 & 30 & 738 & 30 \\
\hline 2 & 50 & 45 & 51 & 899 & 90 & 1130 & 22 \\
\hline 3 & 14 & 60 & 20 & 1101 & 90 & 1461 & 73 \\
\hline 4 & 60 & 30 & 57 & 1086 & 60 & 1166 & 20 \\
\hline mean & 39 & 41 & 38 & 1082 & 68 & 1124 & 36 \\
\hline \pm S.E. & 10 & 7.2 & 9.2 & 70 & 14 & 148 & 12 \\
\hline
\end{tabular}



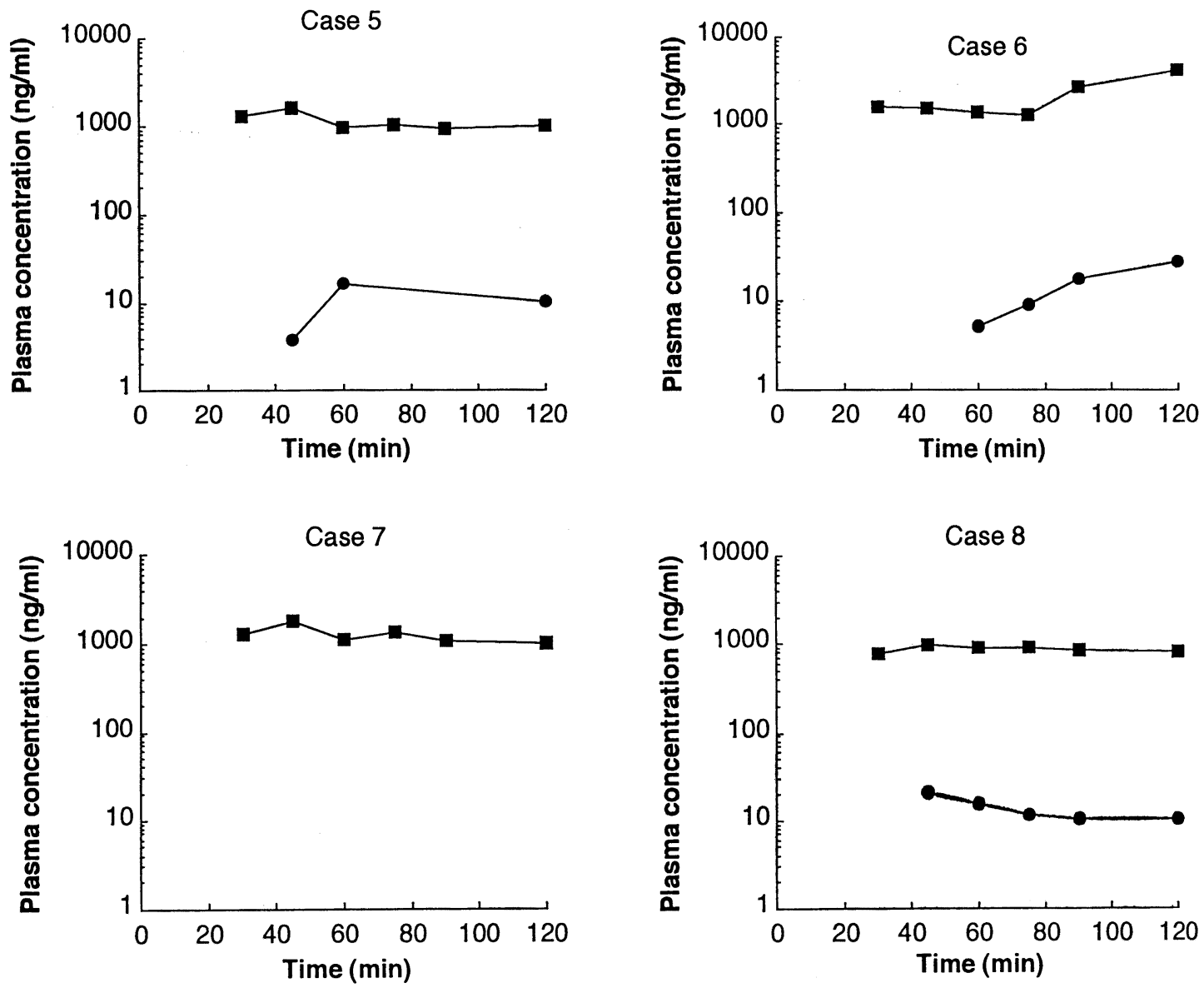

Fig. 2. Plasma Concentration-Time Curves of Morphine and M-3-G following Rectal Administration of Hollow-Type Suppository Containing Morphine Hydrochloride Solution in Patients (No. 5-8) under General Anesthesia during Surgical Operation

Key: •, morphine; $\square, \mathrm{M}-3-\mathrm{G}$.

Table 4. Pharmacokinetic Parameters of Morphine and M-3-G following Rectal Administration of Hollow-Type Suppository Containing Morphine Powder

\begin{tabular}{|c|c|c|c|c|c|c|c|}
\hline \multirow[b]{2}{*}{$\begin{array}{l}\text { Case } \\
\text { No. }\end{array}$} & \multicolumn{3}{|c|}{ Morphine } & \multicolumn{3}{|c|}{ M-3-G } & \multirow{2}{*}{$\begin{array}{l}\text { AUC ratio } \\
\text { M-3-G/ } \\
\text { Morphine }\end{array}$} \\
\hline & $\begin{array}{l}\text { Cmax } \\
(\mathrm{ng} / \mathrm{ml})\end{array}$ & $\begin{array}{l}\operatorname{tmax} \\
(\min )\end{array}$ & $\begin{array}{l}\text { AUCMOO-2 } \\
(\mathrm{h} \cdot \mathrm{ng} / \mathrm{ml}) \\
\end{array}$ & $\begin{array}{l}C \max \\
(\mathrm{ng} / \mathrm{ml}) \\
\end{array}$ & $\begin{array}{l}\operatorname{tmax} \\
(\min )\end{array}$ & $\begin{array}{l}\text { AUC3Go-2 } \\
(\mathrm{h} \cdot \mathrm{ng} / \mathrm{ml})\end{array}$ & \\
\hline 5 & 17 & 60 & 17 & 1614 & 45 & 1990 & 117 \\
\hline 6 & 27 & 120 & 19 & 4066 & 120 & 3632 & 191 \\
\hline 7 & - & - & - & 1832 & 45 & 2214 & - \\
\hline 8 & 20 & 45 & 23 & 959 & 45 & 1500 & 65 \\
\hline mean & 21 & 75 & 20 & 2118 & 64 & 2334 & 124 \\
\hline $\pm S . E$. & 3.0 & 23 & 1.8 & 675 & 14 & 458 & 36 \\
\hline
\end{tabular}


ると考えられる。

モルヒネは大きく初回通過効果を受けていると 考えられることから，モルヒネの $\mathrm{AUCmo}_{0-2}$ と M-3-G の AUC3G A-2 $_{0}$ の比を Table 3 または 4 に併記した. 水溶液充媜坐剂投与後の AUC の比 は, 経口投与後に打ける Osborne らの報告の 值 ${ }^{13)}$ に比べ小さい值を示した. このことは水溶液 充填坐剂は経口投与に比べ初回通過効果をより回 避するものと考えられる. 塩酸モルヒネ一乳糖10 倍散充媜坐剂の AUC の比は, 水溶液投与に比べ 有意に大きな值が得られた。一般に初回通過効果 の大きい薬物の代謝は, 肝蔵を通過する速度およ び濃度に左右される. 直腸に打いて塩酸モルヒネ 一乳糖10倍散充填坐剤からの溶出は水溶液に比べ 遅いと考えられ, 肝蔵での代謝を大きく受けたも のと思われる.これらのことから，值腸における 坐剂への薬物の添加形態は, 生物学的利用能を大 きく変動する要因となるものと考えられる.

謝辞 M-3-G を譲渡して頂きました九州大学薬学 部, 小栗一太教授, 塩酸ナロルフィンを譲渡して頂き ました大日本製薬株式会社ならびに Witepsol 基剤を 提供して頂きましたミッバ貿易株式会社に深く感謝致 します.

\section{引用文献}

1) (第16報): Y. Matsumoto, Y. Watanabe, I. Yamamoto and M. Matsumoto, Biol. Pharm. Bull., 16, 150-153 (1993).

2）佐藤 尚, 植木邦治, 福野剛樹, 水内義明, 大久
保利之, 仲野登喜子, 漆畑一, 鈴木文行, 越川 芳一, 水口公信, 医療, 36, 1237-1241 (1989).

3）木船陽子, 森谷栄司, 竹下八州男, 河島 進, 病 院薬学, 17, 414-420 (1991).

4) 水口公信, 武田文和, 平賀一陽, 臨㦿医薬, 6, 2639-2655 (1990).

5）坪内慎二, 多田昭博, 勝山善彦, 全田 浩, 関 弘, 松本宜明, 渡辺善照, 松本光雄, 病院薬学, 18, 633-637 (1992).

6) 松本宜明, 中尾照男, 湯浅宏美, 赤井清紀, 渡辺 善照, 鈴木由美, 松本光雄, 診断 と治療, 79, 1717-1722 (1991).

7) 渡辺善照, 松本宜明, 松本光雄, 薬局, 40, 15991602 (1989).

8) 大坂麻里枝, 三鍋敦子, 浅利 遙, 松本宜明, 渡 辺善照, 松本光雄, 臨床麻酤, 15, 1037-1040 (1991).

9) J. O. Svensson, J. Chromatogr., 375, 174-178 (1986).

10) M. Konishi, H. Hashimoto, J. Pharm. Sci., 79, 379-383 (1990).

11) N. M. Ellison, G. O. Lewis, Clinical Pharmacy, 3, 614-617 (1984).

12) Y. Matsumoto, Y. Watanabe, N. Hori, M. Matsumoto, F. Iizuka, N. Hino, S. Tsuyuki, K. Morioka and T. Okura., Yakuzaigaku, 50, 53-57 (1990).

13) R. Osborne, S. Joel, D.Trew, M. Slevin, Clin. Pharmacol. Ther., 47, 12-19 (1990).

14) Y. Watanabe, Y. Matsumoto, K. Baba and M. Matsumoto, J. Pharmacobio-Dyn., 9, 526531 (1986). 